\title{
Development of Comparative Toxicity Potentials of TiO2 Nanoparticles for Use in Life Cycle Assessment
}

Ettrup, Kim; Kounina, Anna; Hansen, Steffen Foss; Meesters, Johannes A J; Blikra Vea, Eldbjørg; Laurent, Alexis

\section{Published in:}

Environmental Science and Technology

Link to article, DOI:

10.1021/acs.est.6b05049

Publication date:

2017

Document Version

Peer reviewed version

Link back to DTU Orbit

Citation (APA):

Ettrup, K., Kounina, A., Hansen, S. F., Meesters, J. A. J., Blikra Vea, E., \& Laurent, A. (2017). Development of Comparative Toxicity Potentials of TiO Nanoparticles for Use in Life Cycle Assessment. Environmental Science

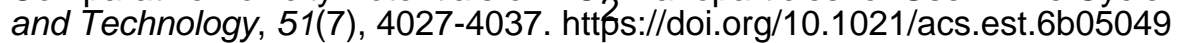

\section{General rights}

Copyright and moral rights for the publications made accessible in the public portal are retained by the authors and/or other copyright owners and it is a condition of accessing publications that users recognise and abide by the legal requirements associated with these rights.

- Users may download and print one copy of any publication from the public portal for the purpose of private study or research.

- You may not further distribute the material or use it for any profit-making activity or commercial gain

- You may freely distribute the URL identifying the publication in the public portal 


\section{Development of comparative toxicity potentials of $\mathrm{TiO}_{2}$}

\section{nanoparticles for use in life cycle assessment}

${ }^{1}$ Division for Quantitative Sustainability Assessment (QSA), Department of Management

9 Engineering, Technical University of Denmark, Bygningstorvet 116B, 2800 Kgs. Lyngby, Denmark

$10 \quad{ }^{2}$ Quantis, EPFL Innovation Park, Bât D, 1015 Lausanne, Switzerland

$11{ }^{3}$ Department of Environmental Engineering, Technical University of Denmark, Building 115, 2800

12 Kgs. Lyngby, Denmark

$13{ }^{4}$ Institute for Water and Wetland Research, Department of Environmental Science, Radboud

14 University Nijmegen, P.O. Box 9010, NL-6500 GL Nijmegen, The Netherlands

15

16 
Ettrup K., Kounina A., Hansen S. F., Meesters J. A. J., Vea E. B., Laurent A., 2017. Development of comparative toxicity potentials of $\mathrm{TiO}_{2}$ nanoparticles for use in life cycle assessment. Environmental Science and Technology 51, 4027-4037. DOI: 10.1021/acs.est.6b05049.

19

20

21

22

23

24

25

26

27

28

29

30

31

32

33

34

35

36

37

38

39

\section{Abstract}

Studies have shown that releases of nanoparticles may take place through the life cycle of products embedding nanomaterials, thus resulting in potential impacts on ecosystems and human health.

While several life cycle assessment (LCA) studies have assessed such products, only a few of them have quantitatively addressed the toxic impacts caused by released nanoparticles, thus leading to potential biases in their conclusions. Here, we address this gap and aim to provide a framework for calculating comparative toxicity potentials (CTP) for nanoparticles and derive CTP values for $\mathrm{TiO}_{2}$ nanoparticles $\left(\mathrm{TiO}_{2}-\mathrm{NP}\right)$ for use in LCA. We adapted the USEtox 2.0 consensus model to integrate the SimpleBox4Nano fate model, and we populated the resulting model with $\mathrm{TiO}_{2}-\mathrm{NP}$ specific data. We thus calculated CTP values for $\mathrm{TiO}_{2}$ nanoparticles for air, water and soil emission compartments for freshwater ecotoxicity and human toxicity, both cancer effects and non-cancer effects. Our results appeared plausible after benchmarking with CTPs for other nanoparticles and substances present in the USEtox database, while large differences were observed with CTP values for $\mathrm{TiO}_{2}$ nanoparticles published in earlier studies. Assumptions, which were performed in those previous studies because of lack of data and knowledge at the time they were made, primarily explain such discrepancies. For future assessment of potential toxic impacts of $\mathrm{TiO}_{2}$ nanoparticles in LCA studies, we therefore recommend the use of our calculated CTP.

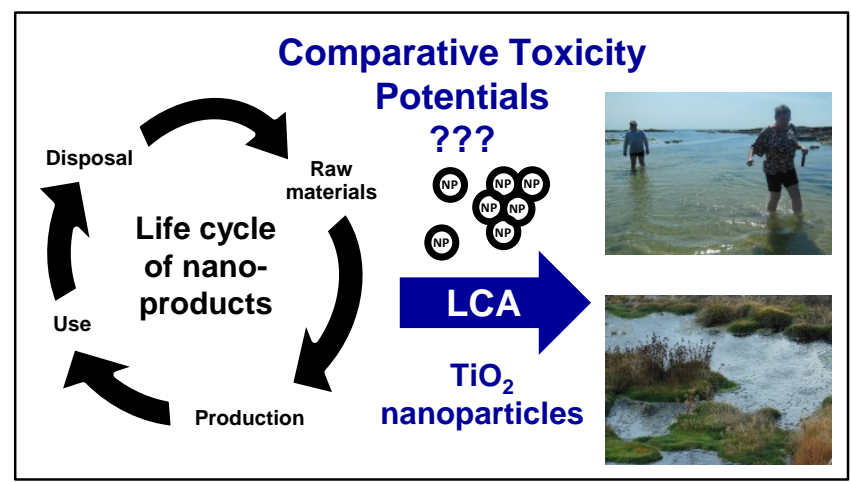


Ettrup K., Kounina A., Hansen S. F., Meesters J. A. J., Vea E. B., Laurent A., 2017. Development of comparative toxicity potentials of $\mathrm{TiO}_{2}$ nanoparticles for use in life cycle assessment. Environmental Science and Technology 51, 4027-4037. DOI: 10.1021/acs.est.6b05049.

\section{Introduction}

Owing to their physicochemical properties, such as high surface areas and small sizes, nanomaterials have been increasingly applied in various commodities over the past decade, bringing optimized strengths and efficiencies compared to conventional products. When embedding nanomaterials in product matrices, their emissions might occur through the life cycle of the resulting nano-products. ${ }^{1-4}$ Direct releases during the manufacturing of the nanomaterials may thus take place. ${ }^{5}$ Likewise, depending on the type of location of the nanomaterial in the product matrices, e.g. suspensions in liquids or surface-bound, and on the type of handling, the use and disposal of the nano-products may also lead to potential releases of nanoparticles. ${ }^{1,4,6}$ Several studies have reported the risks and potential impacts to humans and the environment that such releases may cause. ${ }^{7-14}$ To comprehensively assess the environmental impacts of nano-products, it is therefore necessary to quantify the impacts on ecosystems and human health stemming from these releases over the entire life cycle of the nano-products. ${ }^{2,3,15,16}$

To address this need, the most prominent tool is life cycle assessment (LCA). LCA is a tool, which aims at quantifying all relevant environmental impacts of a product or system taken in its life cycle perspective, i.e. from extraction of the raw materials through its production and use up to its final disposal. ${ }^{17}$ In practice, inventories of pollutant emissions aggregated over the system life cycle are translated into potential impact indicators using characterization factors from life cycle impact assessment (LCIA) methods. These LCIA methods rely on models describing the cause-effect chain from the emissions of a substance to its resulting impacts on ecosystems or human health. To characterize the impacts caused by the toxicity of emitted substances on freshwater ecosystems (termed "freshwater ecotoxicity" in the following) and human health (termed "human toxicity"), the European Commission’s International Reference Life Cycle Data System (ILCD) and the US

Environmental Protection Agency recommended the USEtox model as best LCIA practice. ${ }^{18-20}$ The 4 USEtox model is a consensus-based model, which allows calculating globally-applicable 
Ettrup K., Kounina A., Hansen S. F., Meesters J. A. J., Vea E. B., Laurent A., 2017. Development of comparative toxicity potentials of $\mathrm{TiO}_{2}$ nanoparticles for use in life cycle assessment. Environmental Science and Technology 51, 4027-4037. DOI: 10.1021/acs.est.6b05049.

characterization factors or comparative toxicity potentials (CTP) for assessing freshwater ecotoxicity and human toxicity differentiated into cancer effects and non-cancer effects. ${ }^{21,22}$ To date, more than fifty studies have applied LCA to nano-products. ${ }^{15,23}$ However, most of them have left out the assessment of potential impacts from released nanoparticles. ${ }^{15,24}$ Until now, only twelve studies have investigated the characterization of toxic impacts caused by released nanoparticles. Among these studies, five addressed nanosilver and only accounted for the dissolved fractions thus neglecting potential impact of pristine particles. ${ }^{25-29}$ Three studies focused on CTP for freshwater ecotoxicity of carbon nanotubes, ${ }^{30}$ graphene oxide ${ }^{31}$ and copper nanoparticles. ${ }^{32}$ Four studies developed CTP for $\mathrm{TiO}_{2}$ nanoparticles for freshwater ecotoxicity ${ }^{28,33,34}$ and for human toxicity $^{35}$ (only for airborne emissions). Most of these studies focus on a specific toxic impact category and/or emission compartment, and none provides CTP for both ecotoxicity and human toxicity impacts and for all emission compartments (air, water, soil), all being necessary for the conduct of comprehensive LCA studies. Taken altogether, the four publications focusing on $\mathrm{TiO}_{2}$ nanoparticles come close to cover all impacts and emission compartments; however, inconsistencies were identified in the determination of the CTP proposed in them, compromising their usefulness in case studies -see Sections 3.5 and 3.6. Considering the large number of nanoproducts on the market, ${ }^{4,36-39}$ the overall limited number of studies addressing the comprehensive derivation of nano-specific comparative toxicity potentials is therefore alarming. Even though science lags behind to adequately assess the toxicity of nanoparticles, there is a need to build experience in developing LCIA of nanoparticles and in applying the resulting CTPs to case studies. ${ }^{24}$ In this context, we therefore aim to (i) adapt the USEtox modelling framework in its currently available version (v.2.0), including the integration of recent advances in environmental fate modelling of nanoparticles, to allow for impact assessment of nanoparticles; and (ii) apply the adapted USEtox model to $\mathrm{TiO}_{2}$ nanoparticles to calculate consistent CTPs for freshwater ecotoxicity and human toxicity (both cancer and non-cancer effects) for emissions to air, water and 
Ettrup K., Kounina A., Hansen S. F., Meesters J. A. J., Vea E. B., Laurent A., 2017. Development of comparative toxicity potentials of $\mathrm{TiO}_{2}$ nanoparticles for use in life cycle assessment. Environmental Science and Technology 51, 4027-4037. DOI: 10.1021/acs.est.6b05049.

soil compartments that can replace published values. The selection of $\mathrm{TiO}_{2}$ nanoparticles was made as it is one of the most used nanomaterials on the market and one of the most studied nanoparticles in toxicology, ${ }^{36,39}$ and it also requires updating of the CTP values proposed in recently-published studies by Salieri et al. ${ }^{33}$, Miseljic and Olsen ${ }^{23}$, Hischier et al. ${ }^{34}$ and Pini et al. ${ }^{35}$ (see Sections 3.33.5 and 4).

\section{Methods}

\subsection{USEtox framework}

The USEtox model (http://usetox.org) is set up as a framework which combines matrices relating to the fate, exposure and effects of a given substance. ${ }^{21,40,41}$ In this study, these matrices were determined by identifying relevant data in relation to the exposure and effects of nanoparticles and by altering the fate modelling to account for specific nanoparticle behavior. The version 2.0 of USEtox was used as basis in that effort, and the CTPs were calculated according to Equation 1.

$\overline{C T P}=\overline{F F} \times \overline{X F} \times \overline{E F} \quad$ Equation 1

The fate factors (FF) represent the substance residence time in a given compartment in unit of time (in days). The exposure factors (XF) relate a substance concentration to its actual intake (in day ${ }^{-1}$ for human intake; dimensionless for ecosystems exposure factor). The effect factor (EF) for freshwater ecotoxicity characterizes the fraction of species potentially affected from exposure to the substance and is expressed as a potentially affected fraction of species (PAF) over a volume per mass of exposed substances (in PAF. $\mathrm{m}^{3} / \mathrm{kg}$-exposed or $\mathrm{m}^{3} / \mathrm{kg}$-exposed). The EFs for human toxicity relate the amount of substance taken in by the population via inhalation or ingestion to the probability of adverse effects (carcinogenic or non-carcinogenic effects) of the substance in the 
Ettrup K., Kounina A., Hansen S. F., Meesters J. A. J., Vea E. B., Laurent A., 2017. Development of comparative toxicity potentials of $\mathrm{TiO}_{2}$ nanoparticles for use in life cycle assessment. Environmental Science and Technology 51, 4027-4037. DOI: 10.1021/acs.est.6b05049.

114 human body; they are expressed in the unit of cases/kg-intake. The resulting CTPs are expressed in 115 potentially affected fraction of species (PAF) over time and volume of water per mass of emitted 116 substances for freshwater ecotoxicity (in PAF.m ${ }^{3} . \mathrm{d} / \mathrm{kg}$-nanoparticles emitted) or in number of 117 potential cancer or non-cancer cases per mass of emitted substances for human toxicity (cases/kg118 nanoparticles emitted).

119 In the following subsections, each factor is individually and critically evaluated and adapted to 120 account for the complexity of the nano-specific properties. Some of the factors may be size121 dependent. Wherever possible, the particle size was differentiated, and a default (arbitrary) primary size of $21 \mathrm{~nm}$ (diameter) was considered in the calculation of the comparative toxicity potentials; this size is commonly found in particles tested in toxicological studies (e.g. see Table S4).

\subsection{Fate factors}

The FF determines the concentration in a given compartment to the quantity released by applying multimedia mass balance modelling. ${ }^{21}$ USEtox fate modelling for conventional substances accounts for removal processes, like degradation, burial into sediment, leaching, and intermediate transports between compartments, which are either diffusive or advective. ${ }^{42}$ However, as discrepancies between the fate of conventional chemicals and nanomaterials have been reported, e.g. in water ${ }^{43}$, the fate modelling requires adaptation. ${ }^{44}$ Two main approaches for modelling the fate of nanoparticles have been proposed in the literature, with the fate and transport of the nanoparticles being modelled either through models relying on partition coefficients or via the use of kinetic models and attachment efficiency $\alpha$. On-going discussions remain on which approach is better suited for providing parsimony and accuracy (see for example refs. 45-48). In the present study, we have used the Simplebox4nano (SB4N) model, which relies on the Smoluchowski equation to derive attachment rates between ENPs and the natural particles occurring as colloidal particles in 
Ettrup K., Kounina A., Hansen S. F., Meesters J. A. J., Vea E. B., Laurent A., 2017. Development of comparative toxicity potentials of $\mathrm{TiO}_{2}$ nanoparticles for use in life cycle assessment. Environmental Science and Technology 51, 4027-4037. DOI: 10.1021/acs.est.6b05049.

138 soil and sediment pore waters and for both the colloidal and non-colloidal natural particles that are

139 suspended in surface waters. ${ }^{49,50}$ This choice was motivated by the ability of the model to

140 scientifically capture nanoparticle-specific fate and transport aspects while ensuring compatibility

141 and a relatively easy integration into the USEtox fate modelling framework. The USEtox-defined

142 dimensions of the continental and global boxes were thus adapted to the dimensions of the SB4N

143 model.

144 SB4N is an extension of the chemical multimedia fate model SimpleBox ${ }^{51}$ that calculates chemical

145 concentrations by performing mass balance equations for transport and degradation processes

146 across air, rain, surface waters, soil and sediment. The model matrix of SimpleBox has been

147 extended to that of SB4N, in which (i) the environmental fate of pristine nanoparticles is simulated

148 as well as that of nanoparticles hetero-aggregated with natural colloid particles (<450 nm) and

149 nanoparticles attached to larger natural particles; (ii) dissolution is treated as a removal mechanism

150 because once a nanoparticle has been dissolved, it is no longer a nano-scaled solid particle; and (iii)

151 the rates at which the nanoparticles strive at thermodynamic equilibrium are represented by

152 dissolution, aggregation and attachment rates. ${ }^{49}$

153 The most significant transformation process for nano- $\mathrm{TiO}_{2}$ is the aggregation/agglomeration

154 process. $^{52}$ This process is modeled in SB4N by applying the Derjaguin Landau Verwey Overbeek

155 (DLVO) theory, which calculates the interactions between particle surfaces in dispersions. It should

156 be noted that the experimental ecotoxicological studies have so far mostly been performed on

157 aggregates of suspended nanoparticles, which is often termed homo-aggregation. In the

158 environment, nanoparticles will interact with biota, organic and inorganic entities and form what is

159 known as hetero-aggregates. Until now, a distinction in the ecotoxicity exerted by individual, homo-

160 and hetero-aggregated nanoparticles have not been determined experimentally, ${ }^{53,54}$, and more

161 environmentally-relevant studies are still required to provide insights into that question. ${ }^{55}$

162 Therefore, in the absence of further information, the free and homo- and hetero-aggregated particles 
Ettrup K., Kounina A., Hansen S. F., Meesters J. A. J., Vea E. B., Laurent A., 2017. Development of comparative toxicity potentials of $\mathrm{TiO}_{2}$ nanoparticles for use in life cycle assessment. Environmental Science and Technology 51, 4027-4037. DOI: 10.1021/acs.est.6b05049.

163 are assumed to be bioavailable in the derivation of the fate factors. ${ }^{50}$ Full documentation of the 164 modelling of the aggregation mechanisms and the associated input parameters is available in 165 Supporting Methods and Table S1.

\subsection{Exposure factors}

The exposure factor (XF) for freshwater ecotoxicity of conventional substances is calculated as the dissolved fraction of the chemical in freshwater. ${ }^{42}$ For nanoparticles, the consideration of both free and aggregated particles as bioavailable in freshwater environment makes XF for freshwater ecotoxicity set to 1 (see Section 2.2). With regard to human exposure, several intake pathways exist and are subdivided into direct and indirect exposure in the USEtox model -see Supporting Methods. Direct exposure can occur through inhalation of contaminated air or ingestion of contaminated drinking water, and the modelling of these impact pathways rely on USEtox landscape parameters, which were left unchanged in the model. Dermal exposure, which is a relevant route to address for

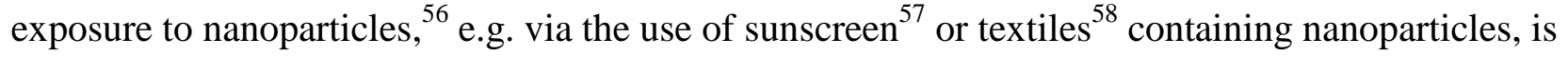
not encompassed in the USEtox 2.0 model and hence was disregarded in the current study. Indirect exposure covers the ingestion of agricultural produce (divided into above- and below-ground produce), meat, dairy products and fish ${ }^{40}$, and bioaccumulation factors (BAF) corresponding to these exposure pathways are needed. ${ }^{42}$ To the authors' knowledge, no studies reporting biotransformation factors (BTF) for meat or milk exist. Therefore, these two exposure pathways were neglected, and only bioaccumulation factors for fish $\left(\mathrm{BAF}_{\text {fish }}\right)$, above-ground produce (BAF $\left.{ }_{\text {above-ground }}\right)$ and below-ground produce $\left(\mathrm{BAF}_{\text {below-ground }}\right)$ were addressed here.

BAF for fish is determined as the ratio of the concentration in the organism over the concentration in the surrounding water, taking into account all exposure routes. ${ }^{59}$ The more accurate and preferred 
Ettrup K., Kounina A., Hansen S. F., Meesters J. A. J., Vea E. B., Laurent A., 2017. Development of comparative toxicity potentials of $\mathrm{TiO}_{2}$ nanoparticles for use in life cycle assessment. Environmental Science and Technology 51, 4027-4037. DOI: 10.1021/acs.est.6b05049.

186 approach in USEtox is to use experimentally determined $\mathrm{BAF}_{\text {fish }}$ values. ${ }^{40}$ A literature review was 187 therefore conducted to identify the most suited $\mathrm{BAF}_{\text {fish }}$-see details in Supporting Methods.

$188 \mathrm{BAF}_{\text {below-ground }}$ can be determined based on the root concentration factor (RCF) with the formula: $189 \mathrm{BAF}_{\text {below-ground }}=\left(\rho_{\text {soil/ }} \rho_{\text {plant }}\right) \mathrm{x}(0.8 \mathrm{RCF})$, where $\rho_{\text {soil }}$ and $\rho_{\text {plant }}$ are the bulk densities of soil and plant, 190 respectively. ${ }^{40}$ As a standard methodology in USEtox, the RCF is determined based on the 191 substance octanol-water partition coefficient $\left(\mathrm{K}_{\mathrm{ow}}\right) \cdot{ }^{40}$ However, as this coefficient is not applicable 192 for nanoparticles ${ }^{60}$, an alternative approach was adopted based on correlation models for the transfer 193 of chemicals from soil solutions to roots developed by Briggs et al. ${ }^{61}$ RCF can thus be determined 194 as the ratio of the particle concentration in the root and that in the soil water.

$\mathrm{BAF}_{\text {above-ground }}$ is difficult to determine solely based on experimental data because of the complexity behind the root uptake, air/plant uptake and translocation mechanisms. To measure the plant uptake 197 of organic chemicals, experiments have been conducted in exposure chambers under steady-state exposure conditions. Unlike for organic chemicals, ${ }^{62}$ for which experiments to measure plant uptake have been conducted, no such study could be retrieved for nanoparticles. To predict the BAF aboveground, mass balance modelling like that adapted in USEtox by Trapp and Matthies ${ }^{63}$ is required.

201 However the strong dependency on $\mathrm{K}_{\mathrm{ow}}$ in its current form renders it inapplicable to nanoparticles. ${ }^{60}$ 202 In the present study, the $\mathrm{BAF}_{\text {above-ground }}$ value was therefore assumed identical to the $\mathrm{BAF}_{\text {below-ground }}$. 203 Further research to address this gap should be undertaken.

\subsection{Effect factors for freshwater ecotoxicity}

206 The EF is defined as: $\mathrm{EF}=0.5 / \mathrm{HC} 0_{\mathrm{EC} 50}$, with $\mathrm{HC} 50_{\mathrm{EC} 50}$ being the hazard concentration, at which $20750 \%$ of the species are exposed to a concentration above their EC50. ${ }^{41}$ In USEtox, the HC50 value 208 is calculated as the geometric mean of all available EC50 values for the different species, the choice 
Ettrup K., Kounina A., Hansen S. F., Meesters J. A. J., Vea E. B., Laurent A., 2017. Development of comparative toxicity potentials of $\mathrm{TiO}_{2}$ nanoparticles for use in life cycle assessment. Environmental Science and Technology 51, 4027-4037. DOI: 10.1021/acs.est.6b05049.

209 of the geometric over the arithmetic means being justified by the need to find best estimates in

210 LCIA modelling and the stronger robustness in cases of limited data sets. ${ }^{64,65}$

211 To derive EFs for nano-sized $\mathrm{TiO}_{2}$, a critical literature review of studies testing ecotoxicity of $\mathrm{TiO}_{2}$ 212 nanoparticles was first conducted (see Supporting Methods). To ensure quality of the data, this step 213 was complemented by shortlisting the retrieved studies according to 3 conditions: (1) only studies 214 stating an EC50; (2) only studies using tests following standardized test methods (ISO, OECD, 215 ATSM etc.); and (3) excluding tests with severe alterations. A final classification of the retained 216 studies into five different sets (some of them being subsets of others) depending on a number of 217 criteria was performed to test the nano-specificities of the EF. Supporting Methods provide detailed 218 descriptions of these sets of studies, each of them leading to the determination of a corresponding 219 EF, which was interpreted as part of a sensitivity analysis (see Section 3.3).

\subsection{Effect factors for human toxicity}

In the USEtox model, the EFs for human toxicity are distinguished between carcinogenic and noncarcinogenic effects, each of them being further differentiated between inhalation and ingestion routes. $^{21}$ The effect factor relies on the assumption of linearity in a concentration-response curve up 225 to the point where the lifetime disease probability is 0.5, and is defined as EF $=0.5 / \mathrm{ED} 50$, with ED50 (in kg-intake/person over lifetime) being the lifetime intake dose resulting in a $50 \%$ increased probability of effects.

228 To determine ED50 for non-carcinogenic effects of $\mathrm{TiO}_{2}$ nanoparticles, the study conducted by

229 Laurent et al. ${ }^{66}$ was used. In this study, a critical review of in vivo studies was performed and 230 relationships between non-observed adverse effect levels (NOAEL) and the primary particle sizes 231 of the particles were investigated. Statistically-significant associations were identified, although some uncertainties reside in the numerical estimates due to the inability to capture other possibly 
Ettrup K., Kounina A., Hansen S. F., Meesters J. A. J., Vea E. B., Laurent A., 2017. Development of comparative toxicity potentials of $\mathrm{TiO}_{2}$ nanoparticles for use in life cycle assessment. Environmental Science and Technology 51, 4027-4037. DOI: 10.1021/acs.est.6b05049.

233 influential physicochemical properties, e.g. surface coatings. ${ }^{66}$ Expressions of NOAEL for humans

234 as a function of the particle size were thus derived and recommended for use in $\mathrm{LCIA}_{\text {of }} \mathrm{TiO}_{2}$

235 nanoparticles until new knowledge allows further refinement. ${ }^{66}$ Effect factors for both inhalation

236 and ingestion routes, considering a default particle size of $21 \mathrm{~nm}$ (see Section 2.1), were derived

237 using Equations S9 and S10. Further details are available in Supporting Methods.

238 To derive the EF for carcinogenic effects of $\mathrm{TiO}_{2}$ nanoparticles via ingestion route, the critical 239 review by Jovanovic ${ }^{67}$ focusing on public health regulations regarding oral ingestion of $\mathrm{TiO}_{2}$ was 240 used. With regard to cancer effects via inhalation, the intake dose reported by Heinrich et al. ${ }^{68}$ on

241 rats was used as inputs to derive an EDx. ${ }^{69}$ Assuming linearity in the dose-response curve, as

242 demonstrated between carcinogenic effects and low effect doses by Crettaz et al. ${ }^{69}$, an effect factor 243 defined as EF $=(\mathrm{x} / 100) / \mathrm{EDx}$, was then derived. Detailed calculations are reported in Supporting 244 Methods.

245 In EF for both cancer and non-cancer effects, it is important to note that, in addition to the lack of 246 data (e.g. only one usable study for cancer effects via inhalation), most extrapolations ( e.g. from 247 animal to humans) stem from conversion factors derived from chemical toxicological studies, and 248 discrepancies may occur when addressing specific nanoparticle behaviors. Considering the lack of 249 insight into this source of uncertainties, we therefore followed the conventional methodology for 250 deriving EF as performed in the USEtox model. Further research is however needed to test these 251 assumptions for nanoparticles and refine the derived EF.

\section{Results and discussion}

254 The different factors for the fate, exposure and effects of nano- $\mathrm{TiO}_{2}$ as well as the resulting 255 comparative toxicity potentials were derived. These factors are presented and discussed individually 256 in the following sections, with provision of recommended values wherever relevant. The calculated 
Ettrup K., Kounina A., Hansen S. F., Meesters J. A. J., Vea E. B., Laurent A., 2017. Development of comparative toxicity potentials of $\mathrm{TiO}_{2}$ nanoparticles for use in life cycle assessment. Environmental Science and Technology 51, 4027-4037. DOI: 10.1021/acs.est.6b05049.

257 CTPs are based on a modified version of the USEtox model (from v.2.0), which accounts for all 258 developments made in this study and are available to LCA practitioners -see Supporting 259 Information.

\subsection{Fate factors}

262 The physiochemical data collected for the fate modelling for nano- $\mathrm{TiO}_{2}$ are reported in Table S1.

263 These data are based on anatase and rutile crystal forms of $\mathrm{TiO}_{2}$ nanoparticles with an average size 264 of $21 \mathrm{~nm}$ and a considered density of $4.23 \mathrm{E}+3 \mathrm{~kg} / \mathrm{m}^{3}$. In the adapted USEtox model (see Supporting 265 Information), it can be observed that the derived fate factors for the free and aggregated forms in water is found equal to $6.33 \mathrm{E}-1$ day and $4.48 \mathrm{E}+1$ day, respectively. This reflects a strong influence of including the aggregated fraction of nanoparticles on the FF (see also Section 3.5).

268 With the replacement of the USEtox fate model with the SB4N model, a number of relevant 269 differentiation of emission compartments as embedded in USEtox 2.0 are lost in the USEtox 2.0 270 adapted to nanoparticles, e.g. the industrial indoor air compartment (highly relevant for assessing 271 human toxicity). ${ }^{70,71}$ Future works should therefore focus on developing a fate model, which accounts for the nanoparticle specificities while embedding sufficiently differentiated emission

273 compartments to capture all emission situations that may occur in the life cycle of nanoproducts.

\subsection{Exposure factors}

276 Several studies have demonstrated the uptake of nano- $\mathrm{TiO}_{2}$ in fish, including the uptake in gills, 277 brain, skin and other organs. ${ }^{72-76}$ However, none of them have derived BAF values based on the measured concentrations because of difficulties to address nanoparticle properties, in particular the

279 incomplete coverage of uptake routes needed to calculate the BAF. ${ }^{77}$ The uptake from dietary 
Ettrup K., Kounina A., Hansen S. F., Meesters J. A. J., Vea E. B., Laurent A., 2017. Development of comparative toxicity potentials of $\mathrm{TiO}_{2}$ nanoparticles for use in life cycle assessment. Environmental Science and Technology 51, 4027-4037. DOI: 10.1021/acs.est.6b05049.

280

281

282

283

284

285

286

287

288

289

290

291

292

293

294

295

296

297

298

299

300

exposure in the aquatic environment is thus typically neglected in studies, resulting in the determination of bioconcentration factors (BCF) instead of a BAF.

In the current study, two BAF proxies were therefore determined based on BCF values. A first BAF proxy of 21.4 was determined based on the geometric mean of several identified BCF values -see Table S2. A second BCF of 35.3 was derived based on the study by Yeo \& Nam ${ }^{78}$, who set up a microcosm including several trophic levels. Although the use of BCF values as BAF proxies can be acceptable in the absence of better data, Zhu et al. showed that the body burden for D. rerio was higher when exposed to nano- $\mathrm{TiO}_{2}$ contaminated $D$. magna compared to aqueous exposure indicating that the dietary exposure could play a significant role in the uptake of nanoparticles. ${ }^{79}$ Therefore, the BCF value of 35.3 derived from the study by Yeo \& Nam, ${ }^{78}$ who included exposure through both water and diet, was selected as expected to be a closer proxy to an actual BAF.

For below-ground produce, the $\mathrm{BAF}_{\text {below-ground }}$ was calculated as the geometric mean of several BAF values obtained for different plants, for which accumulation and uptake of nano- $\mathrm{TiO}_{2}$ were investigated $^{80,81}$-see Table S3. A BAF below-ground of 2.9 was thus determined. This value appears very low in regards to typical ranges of bioaccumulation factors, thus suggesting that the bioaccumulation of nano- $\mathrm{TiO}_{2}$ in roots, and hence in the below-ground produce, may be very limited.

As indicated in Section 2.4, due to lack of data, the $\mathrm{BAF}_{\text {above-ground }}$ was estimated from the BAF for below-ground produce. They were assumed equal, resulting in a $\mathrm{BAF}_{\text {above-ground }}$ value of 2.9. This assumption seems acceptable as little or no translocation between roots, leaves and fruits have been reported in the majority of studies identified. ${ }^{82-85}$ If no translocation of particles takes place, the $\mathrm{BAF}_{\mathrm{above}-\text { ground }}$ in relation to the soil compartment can be argued to be equal to the concentration in the roots of the plants and thus be equal to the $\mathrm{BAF}_{\text {below-ground. }}$ It should however be noted that translocation were evidenced for other nanoparticles (e.g. Ag, $\mathrm{Zn}, \mathrm{Cu}, \mathrm{Co}$, etc.) indicating that the 
Ettrup K., Kounina A., Hansen S. F., Meesters J. A. J., Vea E. B., Laurent A., 2017. Development of comparative toxicity potentials of $\mathrm{TiO}_{2}$ nanoparticles for use in life cycle assessment. Environmental Science and Technology 51, 4027-4037. DOI: 10.1021/acs.est.6b05049.

304 behavior of nanoparticles in both soil and plant medias is particle-specific and likely depends on their physicochemical properties (e.g. solubility). ${ }^{82,86-88}$

\subsection{Effect factor freshwater ecotoxicity}

From the literature review, a total of 65 relevant publications was identified covering 22 different species -see Table S4. Results for the five sets of EFs are provided in Table S5 and range between 9.4 and 26.9 PAF. $\mathrm{m}^{3} / \mathrm{kg}$-exposed (trophic level). The EF value of $26.9 \mathrm{PAF} \mathrm{m}^{3} / \mathrm{kg}$ is recommended for use as it relies on studies, which were identified as adequately testing ecotoxicity of nanoparticles, i.e. specific requirements were fulfilled in relation to the distinctive behavior of nanoparticles (based on Lützhøft et al. ${ }^{89}$-see Supporting Methods).

314 Two studies can be used for comparison with this finding. Miseljic and Olsen ${ }^{23}$ identified 12 315 studies, which cover data published up to 2011 and resulting in 27 possible endpoints, and reported 316 an EF of 26.1 $\mathrm{PAF} \mathrm{m}^{3} / \mathrm{kg}$ for freshwater ecotoxicity of $\mathrm{TiO}_{2}$, while Salieri et al. ${ }^{33}$, who identified 32 317 studies covering data published up to 2013 and resulting in 30 possible endpoints, reported an EF 318 value of $28.1 \mathrm{PAF} \cdot \mathrm{m}^{3} / \mathrm{kg}$. The value recommended in our study is nearly identical to the values 319 reported in those two sources, which may thus indicate a high consistency.

320 To put the results in perspective, the recommended EF value was compared to the existing EFs in 321 USEtox for both organic and inorganic chemicals (amounting to ca. 2500 chemicals) along with the 322 values reported by Salieri et al. ${ }^{33}$ and Miseljic and Olsen ${ }^{23}$-see Figure S1. The recommended EF 323 for $\mathrm{TiO}_{2}$ is observed to be in the lower range of EF values for both organic and inorganic chemicals. $324 \mathrm{TiO}_{2}$ has been showed to exert low toxicity compared to other metal oxides, like $\mathrm{ZnO}$ or CuO. ${ }^{90,91} \mathrm{It}$ 325 therefore makes plausible the relative positioning of nano- $\mathrm{TiO}_{2}$ among other chemicals reported in 326 USEtox, and thus our recommended EF value. 
Ettrup K., Kounina A., Hansen S. F., Meesters J. A. J., Vea E. B., Laurent A., 2017. Development of comparative toxicity potentials of $\mathrm{TiO}_{2}$ nanoparticles for use in life cycle assessment. Environmental Science and Technology 51, 4027-4037. DOI: 10.1021/acs.est.6b05049.

327 The relative variability in the EF value, ranging 9.4-26.9 $\mathrm{PAF} \mathrm{m}^{3} / \mathrm{kg}$ across the 5 sets at the trophic

328 level (see Table S5) can primarily be explained by the influence that highly sensitive species may

329 have on the results (e.g. protozoa). These observations therefore call for developing specific data

330 selection guidelines to derive consistent EFs for nanoparticles in future studies. Until such

331 guidelines emerge, a 2-step procedure should be followed, using the nano-specific criteria set by

332 Lützhøft, et al. ${ }^{89}$ to shortlist the studies before applying the methodology described in Larsen and

333 Hauschild. ${ }^{64,65}$

\subsection{Effect factors for human toxicity}

The recommended effect factors for human toxicity, cancer and non-cancer effects, are reported in

Table 1. Background documentation pertaining to their determination is available in Supporting

Methods.

Table 1. Recommended EF for nano- $\mathrm{TiO}_{2}$ for human toxicity, cancer and non-cancer effects.

\begin{tabular}{|c|c|c|c|c|}
\hline \multicolumn{2}{|c|}{ Impact/impact pathway } & Value $^{a}$ & Unit & Applicability \\
\hline \multirow{3}{*}{$\begin{array}{l}\text { Human toxicity - } \\
\text { cancer effects }\end{array}$} & $\begin{array}{l}\text { Inhalation } \\
\text { (nanosized) }\end{array}$ & $\begin{array}{c}1.54 \mathrm{E}-1 \\
{[-]}\end{array}$ & $\begin{array}{l}\text { cases } / \mathrm{kg}- \\
\text { inhaled }\end{array}$ & $\begin{array}{l}\text { Applicable for particle sizes } \\
\text { between } 15-40 \mathrm{~nm}\end{array}$ \\
\hline & $\begin{array}{l}\text { Inhalation } \\
\text { (microsized) }\end{array}$ & $\begin{array}{c}1.10 \mathrm{E}-2 \\
{[-]}\end{array}$ & $\begin{array}{l}\text { cases } / \mathrm{kg}- \\
\text { inhaled }\end{array}$ & $\begin{array}{l}\text { Applicable for particle sizes } \\
\text { between } 1.5-1.7 \mu \mathrm{m}\end{array}$ \\
\hline & Ingestion & $\begin{array}{c}0 \\
{[-]} \\
\end{array}$ & $\begin{array}{l}\text { cases } / \mathrm{kg}- \\
\text { ingested }\end{array}$ & No cancer effects assumed \\
\hline \multirow{2}{*}{$\begin{array}{l}\text { Human toxicity - } \\
\text { non-cancer effects }\end{array}$} & Inhalation & $\begin{array}{c}1.15 \\
{[0.38 ; 3.48]}\end{array}$ & $\begin{array}{c}\text { cases } / \mathrm{kg}- \\
\text { inhaled }\end{array}$ & \multirow{2}{*}{$\begin{array}{l}\text { Values set for } 21 \mathrm{~nm} \text { primary } \\
\text { particle size (size dependency } \\
\text { available in Equations S9 and } \\
\text { S10) }\end{array}$} \\
\hline & Ingestion & $\begin{array}{c}2.94 \mathrm{E}-2 \\
{[9.72 \mathrm{E}-3 ; 8.89 \mathrm{E}-2]}\end{array}$ & $\begin{array}{l}\text { cases } / \mathrm{kg}- \\
\text { ingested }\end{array}$ & \\
\hline
\end{tabular}

${ }^{\mathrm{a}}$ Confidence intervals were derived whenever possible and are provided in brackets 
Ettrup K., Kounina A., Hansen S. F., Meesters J. A. J., Vea E. B., Laurent A., 2017. Development of comparative toxicity potentials of $\mathrm{TiO}_{2}$ nanoparticles for use in life cycle assessment. Environmental Science and Technology 51, 4027-4037. DOI: 10.1021/acs.est.6b05049.

345 The obtained EF values from Table 1 were compared to Pini et al. ${ }^{35}$, who published EF values for 346 indoor and outdoor inhalation exposure to $\mathrm{TiO}_{2}$ nanoparticles for both non-cancer and cancer 347 effects. In addition, they were put in perspective with the USEtox 2.0 database of effect factors for 348 organics and inorganics (total of ca. 1000 EF values). Figures S2 and S3 illustrate those 349 comparisons for non-cancer effects and cancer effects, respectively.

350 For non-cancer effects, Pini et al. ${ }^{35}$ report an EF value of 7.26E-3 cases/kg-intake, which is ca. 160 351 times lower than our EF value of 1.15 cases/kg-intake (see Table 1 ). This discrepancy can mainly 352 be explained by the assumption made by Pini et al. ${ }^{35}$ to use a no-observed adverse effect level 353 (NOAEL) value for ingestion exposure when determining an EF for inhalation. As reported in 354 Laurent et al. ${ }^{66}$, NOAELs differ by several orders of magnitude between the two exposure routes, 355 with regression analyses on available toxicological data for $\mathrm{TiO}_{2}$ showing a factor of ca. 40 between 356 the two. ${ }^{66}$ Provided that the extrapolations from NOAELs (expressed as daily chronic intake dose) 357 to ED50 and the subsequent calculations of the EF are the same between ingestion and inhalation 358 routes, ${ }^{21,40}$ a difference observed in the NOAELs between the two routes is thus propagated to the 359 corresponding EF values (see for example the differences of factor ca. 40 between EFs for non360 cancer effects reported in Table 1). The observed underestimation is also suggested when 361 comparing with the EF for inhalation for organics and inorganics reported in USEtox 2.0, where 362 Pini et al.'s EF value falls in the lower 25 percentile of both organics and inorganics -see Figure 363 S2A. In contrast, our recommended EF values for inhalation of nano- $\mathrm{TiO}_{2}$ fall close to the mean of 364 EFs for inorganic chemicals and just above the range of EFs for organic chemicals (Figure S2A). 365 For the ingestion pathway, the EF value provided in the present study falls close to the mean of the 366 organics and just below the inorganics (see Figure S2B). Such comparisons seem reasonable 367 considering the large number of organic and inorganic substances in the USEtox database.

368 With respect to cancer effects via inhalation, Pini et al. ${ }^{35}$ reported an EF value of $1.77 \mathrm{E}+2$ cases $/ \mathrm{kg}-$ 369 inhaled (outdoor emission), which is more than 3 orders of magnitude higher than our reported EF 
Ettrup K., Kounina A., Hansen S. F., Meesters J. A. J., Vea E. B., Laurent A., 2017. Development of comparative toxicity potentials of $\mathrm{TiO}_{2}$ nanoparticles for use in life cycle assessment. Environmental Science and Technology 51, 4027-4037. DOI: 10.1021/acs.est.6b05049.

370 value of 0.15 case/kg-inhaled (Table 1 ). This estimate by Pini et al..$^{35}$ is also observed to range 371 among the top carcinogenic substances in the EF for organics and to be well above any EF of metals reported in USEtox 2.0 for cancer effects (see Figure S3). This is regarded as unrealistic considering the IARC classification of $\mathrm{TiO}_{2}$ as possibly carcinogenic to humans ${ }^{92}$, in contrast to substances like arsenic, nickel or beryllium, all of them being classified as carcinogenic to humans and reported in USEtox 2.0. Based on the study by Laurent et al. ${ }^{66}$, who used the National Institute of Occupational Safety and Health (NIOSH) exposure thresholds ${ }^{93}$, as did Pini et al. ${ }^{35}$, an EF value of 7.4E-2 cases/kg-inhaled should be found when applying the methodology reported by Pini et al. ${ }^{35}$

378 With respect to the ingestion pathway, Jovanović ${ }^{67}$ showed that although nano- $\mathrm{TiO}_{2}$ has the 379 potential for absorption and storage in various organs by mammals, no study has demonstrated that 380 ingestion of $\mathrm{TiO}_{2}$ could induce carcinogenic effects. ${ }^{67,92}$ Therefore, the EF value for carcinogenic 381 effects through ingestion was set to 0 cases / kg-ingested (see Table 1). For non-cancer effects, no comparative study could be done as, to the authors' knowledge, no studies have investigated this exposure route yet.

As indicated in Table 1, a particle size differentiation could only be considered for the EF values for non-cancer effects, following the work by Laurent et al. ${ }^{66}$ When applying Equations S9 and S10, which can be used to determine EF as a function of the size, a decrease of the EFs for non-cancer effects by a factor of ca. 6 was observed between $\mathrm{TiO}_{2}$ nanoparticles with primary size of $10 \mathrm{~nm}$ and 100-nm $\mathrm{TiO}_{2}$ particles. Although not investigated further in this study, such results suggest the relevance to consistently include size differentiation when determining CTP values for nanoparticles. To a larger extent, a differentiation accounting for relevant physicochemical 391 properties of the nanoparticles, e.g. surface treatment or coatings, which may influence the fate, exposure and effects of the nanoparticles, and thus the resulting CTP values, need to be further explored. Such explorative studies, which should additionally match the actual properties of the 
Ettrup K., Kounina A., Hansen S. F., Meesters J. A. J., Vea E. B., Laurent A., 2017. Development of comparative toxicity potentials of $\mathrm{TiO}_{2}$ nanoparticles for use in life cycle assessment. Environmental Science and Technology 51, 4027-4037. DOI: 10.1021/acs.est.6b05049.

nanoparticles released to the environment, however remain currently hampered by the lack of comprehensive and transparent reporting of the tested nanoparticles in toxicological studies. ${ }^{39,55,66,94}$

\subsection{Comparative toxic potentials for freshwater ecotoxicity}

Table 2 shows the comparative toxicity potentials for freshwater ecotoxicity resulting from the combination of the recommended fate, exposure and effect factors described in Sections 3.1-3.3.

Table 2. Comparative toxic potentials (CTPs) for freshwater ecotoxicity of $\mathrm{TiO}_{2}$ nanoparticles

\begin{tabular}{|l|c|}
\hline $\begin{array}{l}\text { Emission } \\
\text { compartments }\end{array}$ & $\begin{array}{c}\text { Comparative Toxic Potentials } \\
\text { (CTUe or PAF.m }{ }^{3} \text {.d/kgemitted }\end{array}$ \\
\hline Emission to air & $6.05 \mathrm{E}+02$ \\
\hline Emission to freshwater & $1.55 \mathrm{E}+03$ \\
\hline Emissions to soil & $1.19 \mathrm{E}+00$ \\
\hline
\end{tabular}

The recommended CTP of 1.55E+03 PAF.m ${ }^{3} . \mathrm{d} / \mathrm{kg}$-emitted for emissions to freshwater (see Table 2) can be compared to the values derived by Salieri et al. ${ }^{33}$ and Miseljic ${ }^{28}$, who reported CTP values of 2.8E-01 and 1.48E-01 PAF.m ${ }^{3} . d /$ kg-emitted, respectively. These published factors are 3-4 orders of magnitude smaller than the CTP developed in the current study -see Figure 1A. This large difference is caused by the inclusion of the toxic impacts of aggregated particles in our model, unlike those of Salieri et al. ${ }^{33}$ and Miseljic ${ }^{28}$. By simulating the disregard of aggregates, the recommended CTP value virtually drops by 3 orders of magnitude to 1.82 PAF.m ${ }^{3} . \mathrm{d} / \mathrm{kg}$-emitted (see Figure 1A). Both studies by Salieri et al. ${ }^{33}$ and Miseljic ${ }^{28}$ modelled aggregation as a removal process in the fate of the nanoparticles, which result in largely underestimated fate factors (and hence CTP values) since a large fraction of the emitted nanoparticles, i.e. all aggregated nanoparticles, end up being removed and are thus not bioavailable to cause effects in the exposed organisms. When conducting ecotoxicity testing on nanoparticles, several studies have reported that the species take up both the pristine and the aggregates, ${ }^{95,96}$ and most of the current toxicological 
Ettrup K., Kounina A., Hansen S. F., Meesters J. A. J., Vea E. B., Laurent A., 2017. Development of comparative toxicity potentials of $\mathrm{TiO}_{2}$ nanoparticles for use in life cycle assessment. Environmental Science and Technology 51, 4027-4037. DOI: 10.1021/acs.est.6b05049.

416 studies, which are used in the determination of EF, are based on suspensions covering both pristine 417 particles and aggregates. ${ }^{97,98}$ Therefore, he inclusion of both states of the particles when deriving the 418 CTPs for nanoparticles, as done in the current study, is strongly recommended.

419 This is also in line with the study by Eckelman et al. ${ }^{30}$ who derived CTP for freshwater ecotoxicity 420 for CNT. The only removal process considered in the latter study was the advection in the ocean, 421 which resulted in a conservative CTP of $2.9 \mathrm{E}+04$ PAF. $\mathrm{m}^{3} . \mathrm{d} / \mathrm{kg}$-emitted to freshwater, thus in a 422 similar range to the CTP derived in our work (ca. 20 times higher than that of $\mathrm{TiO}_{2}$; see Table 2). In 423 two additional studies, Deng et al. ${ }^{31}$ determined a CTP of 7.89E+02 PAF.m ${ }^{3}$.d/ kg-emitted to 424 freshwater for graphene oxide, thus approximately twice lower than our CTP for $\mathrm{TiO}_{2}$ 425 nanoparticles, while Pu et al. ${ }^{32}$ determined a CTP of 5.96E+03 PAF.m ${ }^{3}$.d/ kg-emitted to freshwater 426 for $\mathrm{CuO}$ nanoparticles (with regional variation ranges of 3.87-11.1E+03 PAF.m ${ }^{3} . \mathrm{d} / \mathrm{kg}$ ), hence four 427 times higher than our estimate for $\mathrm{TiO}_{2}$. Although the modelling in these studies vary (e.g. fate), the 428 CTP values are within same orders of magnitude and consistent with reported toxicity rankings (e.g. $429 \mathrm{CuO}$ nanoparticles being more toxic than $\mathrm{TiO}_{2}$ nanoparticles ${ }^{99}$ ), suggesting a relatively good 430 precision of these studies.

431 In the same manner as the effect factors (see Sections 3.3 and 3.4), the obtained comparative 432 toxicity potentials for nano- $\mathrm{TiO}_{2}$ were benchmarked against existing CTP present in the USEtox 433 database for organic and inorganic chemicals - see Figures 1A, 1B and 1C for air, freshwater and 434 soil emission compartments, respectively. The drop of the CTP derived by Salieri et al. ${ }^{33}$ and 435 Miselic $^{28}$ for freshwater emissions at the bottom of the entire USEtox CTP database, which amounts 436 to ca. 2500 organic and 27 inorganic substances, confirms the likelihood that these CTP are largely 437 underestimated (see Figures 1A). In contrast, the CTP values obtained in our study fall within the 438 lower range of CTPs for inorganics and the median or higher range of CTPs for organics, which is considered plausible (see Figures 1A-1C). 

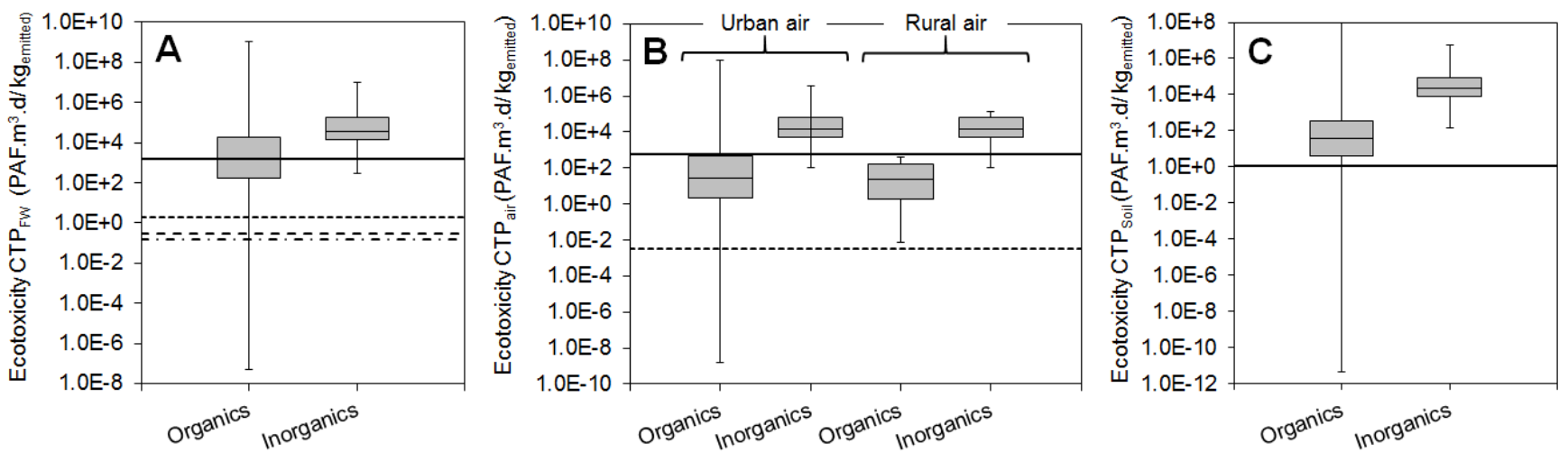

-n-TiO2 (This study)

----n-TiO2 (This study, simulation without aggregates)

- - - Salieri et al. (ref. 33)

-.- Miseljic (ref. 28)

Figure 1. Comparative Toxic Potentials (CTP) for freshwater ecotoxicity of $\mathrm{TiO}_{2}$ nanoparticles plotted against existing USEtox CTP database for emissions to (A) freshwater, (B) air (differentiated between urban air and rural air), and (C) soil compartments. The box plots represent the $25^{\text {th }}$ to the $75^{\text {th }}$ percentile of the CTPs and the upper and lower whiskers represent the maximum and minimum CTPs reported in USEtox (total of 2499 organics and 27 inorganics). Comparisons with Salieri et al. ${ }^{33}$ and Miselic ${ }^{28}$ can only be made for the freshwater emission compartment. Note that the CTPs are plotted on a logarithmic scale.

\subsection{Comparative toxic potentials for human toxicity}

The recommended CTPs for human toxicity for non-carcinogenic and carcinogenic effects are reported in Table 3 for air, freshwater and soil emission compartments. Additional sets of CTPs were also calculated for different scenarios to test the influence of variations in the $\mathrm{BAF}_{\text {fish }}$ derivations and the confidence intervals associated with the EF for human toxicity, non-cancer effects although relatively minor influences were observed (see Table S6).

Table 3. Comparative toxic potentials (CTPs) for human toxicity of $\mathrm{TiO}_{2}$ nanoparticles

\begin{tabular}{|l|c|c|}
\hline \multirow{2}{*}{$\begin{array}{l}\text { Emission } \\
\text { compartments }\end{array}$} & \multicolumn{2}{|c|}{$\begin{array}{c}\text { Comparative Toxic Potentials } \\
\text { (CTUh or cases/kg } \text { emitted }^{\text {) }}\end{array}$} \\
\cline { 2 - 3 } & Cancer effects & Non-cancer effects \\
\hline Emission to air & $1.90 \mathrm{E}-06$ & $1.70 \mathrm{E}-05^{\mathrm{a}}$ \\
\hline Emission to freshwater & $0.00 \mathrm{E}+00$ & $1.25 \mathrm{E}-06^{\mathrm{a}}$ \\
\hline Emissions to soil & $0.00 \mathrm{E}+00$ & $1.42 \mathrm{E}-08^{\mathrm{a}}$ \\
\hline
\end{tabular}


Ettrup K., Kounina A., Hansen S. F., Meesters J. A. J., Vea E. B., Laurent A., 2017. Development of comparative toxicity potentials of $\mathrm{TiO}_{2}$ nanoparticles for use in life cycle assessment. Environmental Science and Technology 51, 4027-4037. DOI: 10.1021/acs.est.6b05049.

459 As observed in Table 3, because the EF via ingestion for carcinogenic effects was estimated to be 460 null (see Section 3.4) and because nanoparticles do not volatilize, the CTPs for carcinogenic effects

461 for freshwater and soil emissions are equal to zero. For the remaining CTP values of Table 3,

462 comparisons with the CTP values reported in Pini et al. ${ }^{35}$ for inhalation exposure (outdoor) and with 463 the CTP database in USEtox v.2.0 can be made -see Figure 2.

464 For non-cancer effects, the CTP values from Pini et al. ${ }^{35}$ plotted in Figure 2B reveal the strong 465 influence of the underestimated EF value, in which ingestion data were used for estimating the 466 inhalation effect factor (see Section 3.4). With regard to cancer effects, abnormally high EF values 467 (see Section 3.4) suggest largely overestimated CTP values in Pini et al. ${ }^{35}$, although some of these 468 overestimations are compensated by lower intake fractions due to different geographical settings 469 (Pini et al. ${ }^{35}$ adapted the USEtox model landscape and population parameters to Swiss conditions) 470 and a different particle size (Pini et al. ${ }^{35}$ considered a particle size of $10 \mathrm{~nm}$ ).In contrast, the CTP 471 values estimated in our study fall in the range of CTPs for organics and below the range for 472 inorganics. Such results seem consistent $\mathrm{asTiO}_{2}$ and titanium in general are not reported to be 473 strongly bioaccumulative nor strongly toxic substances compared to other metals and metalloids 474 (e.g. Ag). ${ }^{100-102}$ 

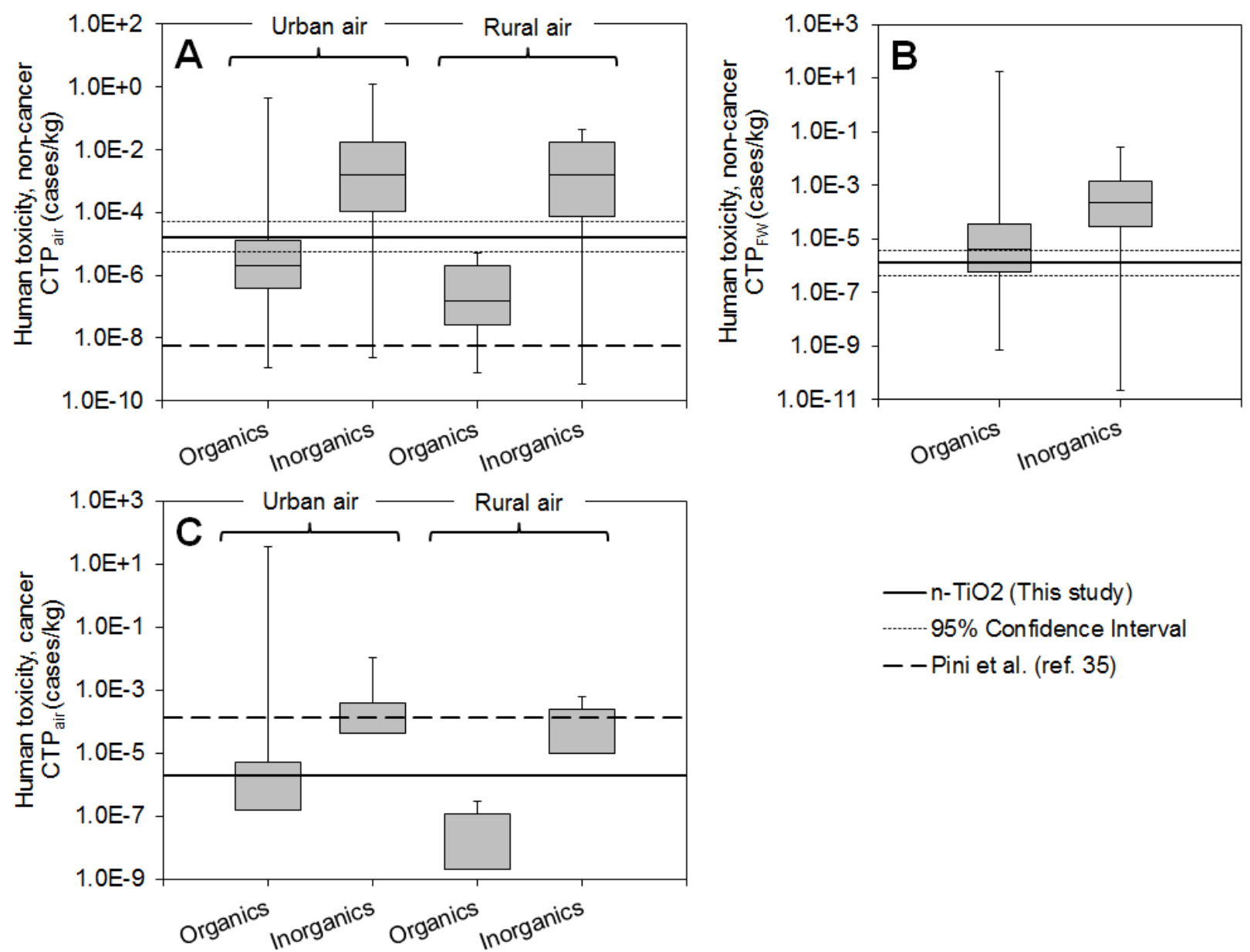

Figure 2. Comparative Toxic Potentials (CTP) for human toxicity of $\mathrm{TiO}_{2}$ nanoparticles plotted against existing USEtox CTP database for (A) non-cancer effects - emissions to air (differentiated between urban and rural air compartments), (B) non-cancer effects - emissions to freshwater, and (C) cancer effects - emissions to air (differentiated between urban and rural air compartments). The box plots represent the $25^{\text {th }}$ to the $75^{\text {th }}$ percentile of the CTPs and the upper and lower whiskers represent the maximum and minimum CTPs reported in USEtox (total of 1024 organics and 15 inorganics for human toxicity, non-cancer effect, and 427 organics and 18 inorganics for cancer effects). No lower whiskers are plotted for cancer effects as some compounds are reported with CTP of 0 CTUh (non-carcinogenic substances). Note that the CTPs are plotted on a logarithmic scale.

\subsection{Applications of CTP and recommendations}

Using the adapted USEtox model, comparative toxicity potentials were developed for $\mathrm{TiO}_{2}$ nanoparticles for characterizing freshwater ecotoxicity and human toxicity, both cancer and non- 
Ettrup K., Kounina A., Hansen S. F., Meesters J. A. J., Vea E. B., Laurent A., 2017. Development of comparative toxicity potentials of $\mathrm{TiO}_{2}$ nanoparticles for use in life cycle assessment. Environmental Science and Technology 51, 4027-4037. DOI: 10.1021/acs.est.6b05049.

491 cancer effects, resulting from emissions to air, water and soil compartments. These CTP values are

492 recommended for application in LCA studies in lieu of values published in earlier studies. ${ }^{23,33-35}$

493 Following the works by Eckelman et al. ${ }^{30}$ and Deng et al. ${ }^{31}$, the present study, and in particular its 494 methodological approach, can be considered as a first step towards more systematic and consistent 495 determinations of CTP for all emission compartments for nanoparticles using the USEtox model as 496 starting point and adjusting it (e.g. fate modelling, effect data, etc.) to integrate the specificities of 497 each nanoparticles. This will enable comparability with chemicals already characterized with the 498 model and thus allow performing life cycle assessment to gauge the potential impacts and relevance 499 of released nanoparticles compared to that of other contributing substances in the life cycle of 500 nanoproducts. To pursue efforts in this direction and enable LCA studies to include impacts of 501 nanoparticles, a number of recommendations for the LCIA modelling of nanoparticles and the 502 applications of derived CTPs are provided in Table 4.

Table 4. Recommendations to LCA practitioners and method developers for life cycle impact

505 assessment of nanoparticles.

\section{Fate modelling}

- $\quad$ Fate modelling should consider nano-specific transformations processes such as attachment efficiencies and dissolution and not be dependent on parameters driving the fate of conventional substances such as partitioning coefficients between dissolved organic carbon, suspended solids, sediment particles or soil particles and water used for the fate of conventional inorganics (see Section 2.2).

- When deriving the final CTPs both the aggregated and the free/pristine particles should be considered bioavailable and thus included in the CTP calculation (see Section 2.2. and 3.5).

\section{Exposure modelling}

- Other exposure routes that are not included in the present USEtox model should be investigated. These include the dermal exposure to engineered nanoparticles present in cosmetics or health care products.

\section{Effect modelling}

- Data applied for deriving effect factors should be evaluated according to documentation of experimental conditions and nanomaterial properties such as aggregation, surface area, etc. (see Section 2.4 and 2.5); alternatively, they should follow the nano-specific guidelines published by OECD. ${ }^{103}$ 
Ettrup K., Kounina A., Hansen S. F., Meesters J. A. J., Vea E. B., Laurent A., 2017. Development of comparative toxicity potentials of $\mathrm{TiO}_{2}$ nanoparticles for use in life cycle assessment. Environmental Science and Technology 51, 4027-4037.

- The possible influence of size on the human toxicity EF should be investigated in further details, particularly for the carcinogenic effects. The influence of other physicochemical properties on the CTP values should also be explored.

\section{Overall CTP development and application in practice}

- There is a need to develop CTPs for nanoparticles matching the actual properties of the released nanoparticles from nano-products. Several studies have evidenced a mismatch between the released nanoparticles and the pristine forms that are used in fate, exposure and effect modelling. The use of CTPs based on pristine nanoparticle data (as done in all existing studies) likely leads to overestimated impact results attributable to engineered nanoparticles, and should be considered with care by LCA practitioners when interpreting their results.

- Owing to the different properties and behavior of each nanoparticle (e.g. carbon nanotubes vs. $\mathrm{TiO}_{2}$ nanoparticles), further research is needed to consistently address the most important transformation processes in the fate modelling and the effects on ecosystems and human health.

\section{Associated content} nanoparticles, (2) a PDF of Supporting Information containing Supporting Methods documenting the detailed methodology and background data for the determination of the fate, exposure and effect factors for freshwater ecotoxicity and human toxicity as well as Supporting Figures and Tables to complement the section Results and Discussion of the manuscript.

\section{Acknowledgements}

515 The authors wish to thank Olivier Jolliet, Henrik F. Larsen, Stig I. Olsen and Lars Sjolding for their 516 commenting and advices in the conduct of this work. AK acknowledges the received funding from 517 the European Union (EU) Seventh Framework Programme (FP7/2007-2013) under Grant 518 Agreement no 263147 (NanoValid-Development of reference methods for hazard identification, 519 risk assessment and LCA of engineered nanomaterials).

\section{References}


Ettrup K., Kounina A., Hansen S. F., Meesters J. A. J., Vea E. B., Laurent A., 2017. Development of comparative toxicity potentials of $\mathrm{TiO}_{2}$ nanoparticles for use in life cycle assessment. Environmental Science and Technology 51, 4027-4037. DOI: 10.1021/acs.est.6b05049.

522 (1) Hansen, S. F.; Michelson, E. S.; Kamper, A.; Borling, P.; Stuer-Lauridsen, F.; Baun, A. Categorization framework to aid exposure assessment of nanomaterials in consumer products. Ecotoxicology 2008, 17 (5), 438-447.

(3) Som, C.; Berges, M.; Chaudhry, Q.; Dusinska, M.; Fernandes, T. F.; Olsen, S. I.; Nowack, B. The importance of life cycle concepts for the development of safe nanoproducts. Toxicology 2010, 269 (2-3), 160-169.

(4) Hansen, S. F.; Heggelund, L. R.; Revilla Besora, P.; Mackevica, A.; Boldrin, A.; Baun, A.

(6) Gottschalk, F.; Nowack, B. The release of engineered nanomaterials to the environment. $J$. Nanoproducts - what is actually available to European consumers? Environ. Sci. Nano 2016, 3 (1), 169-180.

(5) Demou, E.; Stark, W. J.; Hellweg, S. Particle emission and exposure during nanoparticle synthesis in research laboratories. Ann. Occup. Hyg. 2009, 53 (8), 829-838.

\section{Environ. Monit. 2011, 13 (5), 1145-1155.}

(7) Maynard, A. D.; Aitken, R. J.; Butz, T.; Colvin, V.; Donaldson, K.; Oberdörster, G.; Philbert, M. A.; Ryan, J.; Seaton, A.; Stone, V.; et al. Safe handling of nanotechnology. Nature 2006, 444 (7117), 267-269.

(8) Nel, A.; Xia, T.; Mädler, L.; Li, N. Toxic potential of materials at the nanolevel. Science 2006, 311, 622-627.

(9) Oberdörster, G.; Oberdörster, E.; Oberdöster, J. Nanotoxicology: An emerging discipline evolving from studies of ultrafine particles. Environ. Health Perspect. 2005, 113 (7), 823839.

(10) Oberdörster, G. Safety assessment for nanotechnology and nanomedicine: concepts of nanotoxicology. J. Intern. Med. 2010, 267 (1), 89-105.

(11) SCENIHR (Scientific Committee on Emerging and Newly Identified Health Risks). Risk Assessment of Products of Nanotechnologies. European Commission Health and Consumer Protection Directorate - General, Directorate C - Public Health and Risk Assessment, Brussels, BE, 2009. Available at: http://ec.europa.eu/health/ph_risk/committees/04_scenihr/docs/scenihr_o_023.pdf (Accessed January 2017).

(12) Stone, V.; Hankin, S.; Aitken, R.; Aschberger, K.; Baun, A.; Christensen, F.; Fernandes, T.; 
Ettrup K., Kounina A., Hansen S. F., Meesters J. A. J., Vea E. B., Laurent A., 2017. Development of comparative toxicity potentials of $\mathrm{TiO}_{2}$ nanoparticles for use in life cycle assessment. Environmental Science and Technology 51, 4027-4037. DOI: 10.1021/acs.est.6b05049.

Hansen, S. F.; Hartmann, N. B.; Hutchinson, G.; et al. Engineered Nanoparticles: Review of Health and Environmental Safety (ENRHES); ENRHES EU FP 7 project, final report, 2010. Available at: http://www.nanowerk.com/nanotechnology/reports/reportpdf/report133.pdf (Accessed January 2017).

(13) Wiesner, M. R.; Lowry, G. V; Alvarez, P.; Dionysiou, D.; Biswas, P. Assessing the risks of manufactured nanomaterials. Environ. Sci. Technol. 2006, 40 (14), 4336-4345

(14) Bettini, S.; Boutet-robinet, E.; Cartier, C.; Coméra, C.; Gaultier, E.; Dupuy, J.; Naud, N.; Taché, S.; Grysan, P.; Reguer, S.; et al. Food-grade TiO2 impairs intestinal and systemic immune homeostasis, initiates preneoplastic lesions and promotes aberrant crypt development in the rat colon. Scientific Reports 2017, 7, 40373. doi:10.1038/srep40373.

(15) Jolliet, O.; Laurent, A.; Rosenbaum, R. K. Life Cycle Risks and Impacts of Nanotechnologies. In: Nanotechnology and Human Health; Malsch I. and Emond C., Eds.; ISBN 9780849381447. Taylor \& Francis, Boca Raton, FL, USA, 2014, 213-278.

(16) Walker, W. C.; Bosso, C. J.; Eckelman, M.; Isaacs, J. A.; Pourzahedi, L. Integrating life cycle assessment into managing potential EHS risks of engineered nanomaterials: reviewing progress to date. J. Nanoparticle Res. 2015, 46 (3), 344.

(17) Hauschild, M. Z. Assessing environmental impacts in a life-cycle perspective. Environ. Sci. Technol. 2005, 39 (4), 81A-88A.

(18) Hauschild, M. Z.; Goedkoop, M.; Guinée, J.; Heijungs, R.; Huijbregts, M.; Jolliet, O.; Margni, M.; De Schryver, A.; Humbert, S.; Laurent, A.; Sala, S.; Pant, R. Identifying best existing practice for characterization modeling in life cycle impact assessment. Int. J. Life Cycle Assess. 2013, 18 (3), 683-697.

(19) European Commission - Joint Research Centre - Institute for Environment and Sustainability. International Reference Life Cycle Data System (ILCD) Handbook - Recommendations for Life Cycle Impact Assessment in the European context. First edition. EUR24571EN. ISBN 978-92-79-17451-3. Publications Office of the European Union, Luxembourg, LU, 2011.

(20) US-EPA. Tool for the Reduction and Assessment of Chemical and Other Environmental Impacts ( TRACI ) - TRACI version 2.1 User's Guide. US Environmental Protection Agency, Cincinnati, OH, US, 2012.

(21) Rosenbaum, R. K.; Bachmann, T. M.; Gold, L. S.; Huijbregts, M. A. J.; Jolliet, O.; Juraske, R.; Koehler, A.; Larsen, H. F.; MacLeod, M.; Margni, M.; et al. USEtox-the UNEP-SETAC toxicity model: recommended characterisation factors for human toxicity and freshwater ecotoxicity in life cycle impact assessment. Int. J. Life Cycle Assess. 2008, 13, 532-546.

(22) Hauschild, M. Z.; Huijbregts, M.; Jolliet, O.; Macleod, M.; Margni, M.; Rosenbaum, R. K.; 
Ettrup K., Kounina A., Hansen S. F., Meesters J. A. J., Vea E. B., Laurent A., 2017. Development of comparative toxicity potentials of $\mathrm{TiO}_{2}$ nanoparticles for use in life cycle assessment. Environmental Science and Technology 51, 4027-4037. DOI: 10.1021/acs.est.6b05049.

van de Meent, D.; McKone, T. E. Building a model based on scientific consensus for life cycle impact assessment of chemicals: The search for harmony and parsimony. Environ. Sci. Technol. 2008, 42 (19), 7032-7037.

(23) Miseljic, M.; Olsen, S. I. Life-cycle assessment of engineered nanomaterials: A literature review of assessment status. J. Nanopart. Res. 2014, 16 (6), 2427.

(24) Gilbertson, L. M.; Wender, B. A.; Zimmerman, J. B.; Eckelman, M. J. Coordinating modeling and experimental research of engineered nanomaterials to improve life cycle assessment studies. Environ. Sci. Nano 2015, 2 (6), 669-682.

(25) Walser, T.; Demou, E.; Lang, D. J.; Hellweg, S. Prospective environmental life cycle assessment of nanosilver T-Shirts. Environ. Sci. Technol. 2011, 45 (10), 4570-4578.

(26) Meyer, D. E.; Curran, M. A.; Gonzalez, M. A. An examination of silver nanoparticles in socks using screening-level life cycle assessment. J. Nanopart. Res. 2011, 13 (1), 147-156.

(27) Pourzahedi, L.; Eckelman, M. J. Environmental life cycle assessment of nanosilver-enabled bandages. Environ. Sci. Technol. 2015, 49 (1), 361-368.

(28) Miseljic, M. Improvement of methodological and data background for life cycle assessment of nano-metaloxides. PhD Thesis, Technical University of Denmark, Kgs. Lyngby, DK, 2015.

(29) Hicks, A. L.; Gilbertson, L. M.; Yamani, J. S.; Theis, T. L.; Zimmerman, J. B. Life cycle payback estimates of nanosilver enabled textiles under different silver loading, release, and laundering scenarios informed by literature review. Environ. Sci. Technol. 2015, 49 (13), 7529-7542.

(30) Eckelman, M. J.; Mauter, M. S.; Isaacs, J. A.; Elimelech, M. New perspectives on nanomaterial aquatic ecotoxicity: Production impacts exceed direct exposure impacts for carbon nanotoubes. Environ. Sci. Technol. 2012, 46 (5), 2902-2910.

(31) Deng, Y.; Li, J.; Qiu, M.; Yang, F.; Zhang, J.; Yuan, C. Deriving characterization factors on freshwater ecotoxicity of graphene oxide nanomaterial for life cycle impact assessment. Int. J. Life Cycle Assess. 2017, 22 (2), 222-236.

(32) Pu, Y.; Tang, F.; Adam, P.-M.; Laratte, B.; Ionescu, R. E. Fate and characterization factors of nanoparticles in seventeen subcontinental freshwaters: A case study on copper nanoparticles. Environ. Sci. Technol. 2016, 50 (17), 9370-9379.

(33) Salieri, B.; Righi, S.; Pasteris, A.; Olsen, S. I. Freshwater ecotoxicity characterisation factor for metal oxide nanoparticles: A case study on titanium dioxide nanoparticle. Sci. Total Environ. 2015, 505, 494-502.

(34) Hischier, R.; Nowack, B.; Gottschalk, F.; Hincapie, I.; Steinfeldt, M.; Som, C. Life cycle assessment of facade coating systems containing manufactured nanomaterials. J. Nanopart. 
Ettrup K., Kounina A., Hansen S. F., Meesters J. A. J., Vea E. B., Laurent A., 2017. Development of comparative toxicity potentials of $\mathrm{TiO}_{2}$ nanoparticles for use in life cycle assessment. Environmental Science and Technology 51, 4027-4037. DOI: 10.1021/acs.est.6b05049.

Res. 2015, 17 (2), 68.

(35) Pini, M.; Salieri, B.; Ferrari, A. M.; Nowack, B.; Hischier, R. Human health characterization factors of nano-TiO2 for indoor and outdoor environments. Int. J. Life Cycle Assess. 2016, 21 (10), 1452-1462.

(36) Mitrano, D. M.; Motellier, S.; Clavaguera, S.; Nowack, B. Review of nanomaterial aging and transformations through the life cycle of nano-enhanced products. Environ. Int. 2015, 77, $132-147$.

(37) Hendren, C. O.; Mesnard, X.; Dröge, J.;Wiesner, M. R. Estimating Production Data for Five Engineered Nanomaterials As a Basis for Exposure Assessment. Environ. Sci. Technol. 2011, 45, 2562-2569.

(38) Keller, A. A.; McFerran, S.; Lazareva, A.; Suh, S. Global life cycle releases of engineered nanomaterials. J. Nanopart. Res. 2013, 15, 1692.

(39) Krug, H. F. Nanosafety Research — Are We on the Right Track? Angewandte. 2014, 1230412319

(40) Rosenbaum, R. K.; Huijbregts, M. A. J.; Henderson, A. D.; Margni, M.; McKone, T. E.; Meent, D. van de; Hauschild, M. Z.; Shaked, S.; Li, D. S.; Gold, L. S.; et al. USEtox human exposure and toxicity factors for comparative assessment of toxic emissions in life cycle analysis: Sensitivity to key chemical properties. Int. J. Life Cycle Assess. 2011, 16 (8), 710 727.

(41) Henderson, A. D.; Hauschild, M. Z.; Meent, D. van de; Huijbregts, M. A. J.; Larsen, H. F.; Margni, M.; McKone, T. E.; Payet, J.; Rosenbaum, R. K.; Jolliet, O. USEtox fate and ecotoxicity factors for comparative assessment of toxic emissions in life cycle analysis: sensitivity to key chemical properties. Int. J. Life Cycle Assess. 2011, 16 (8), 701-709.

(42) Huijbregts, M.; Hauschild, M.; Jolliet, O.; Margni, M.; Mckone, T.; Rosenbaum, R. K.; van de Meent, D. USEtox User Manual. v1.01. USEtox Team, 2010.

(43) Quik, J. T. K.; Vonk, J. A.; Hansen, S. F.; Baun, A.; van de Meent, D. How to assess exposure of aquatic organisms to manufactured nanoparticles? Environ. Int. 2011, 37 (6), 1068-1077.

(44) Meesters, J. A.; Veltman, K.; Hendriks, A. J.; van de Meent, D. Environmental exposure assessment of engineered nanoparticles: why REACH needs adjustment. Integr. Environ. Assess. Manag. 2013, 9 (3), 15-26.

(45) Praetorius, A.; Tufenkji, N.; Goss, K.; Scheringer, M. The road to nowhere : equilibrium partition coefficients for nanoparticles. Environ. Sci. Nano 2014, 1, 317-323.

(46) Cornelis, G. Fate descriptors for engineered nanoparticles: the good, the bad, and the ugly. 
Ettrup K., Kounina A., Hansen S. F., Meesters J. A. J., Vea E. B., Laurent A., 2017. Development of comparative toxicity potentials of $\mathrm{TiO}_{2}$ nanoparticles for use in life cycle assessment. Environmental Science and Technology 51, 4027-4037.

Environ. Sci. Nano 2015, 2, 19-26.

(47) Dale, A. L.; Casman, E. A.; Lowry, G. V.; Lead, J. R.; Viparelli, E.; Baalousha, M. Modeling nanomaterial environmental fate in aquatic systems. Environ. Sci. Technol. 2015, 49 (5), 2587-2593.

(48) Dale, A. L.; Lowry, V.; Casman, E. A. Much ado about alpha: Reframing the debate over appropriate fate descriptors in nanoparticle environmental risk modeling. Environ. Sci. Nano 2015, 2, 27-32.

(49) Meesters, J. A.; Koelmans, A. A.; Quik, J. T. K.; Hendriks, A. J.; van de Meent, D. Multimedia modeling of engineered nanoparticles with simpleBox4nano: Model definition and evaluation. Environ. Sci. Technol. 2014, 48 (10), 5726-5736.

(50) Meesters, J. A.; Quik, J. T. K.; Koelmans, A. A.; Hendriks, A. J.; van de Meent, D. Multimedia environmental fate and speciation of engineered nanoparticles: A probabilistic modeling approach. Environ. Sci. Nano 2016, 3 (4), 715-727.

(51) Brandes, L.J.; den Hollander, H.; van de Meent, D. SimpleBox 2.0: A nested multimedia fate model for evaluating the environmental fate of chemicals. RIVM Report no. 719101029. National Institute of Public Health and the Environment, Bilthoven, NL, 1996.

(52) Hartmann, N. B.; Skjolding, L. M.; Hansen, S. F.; Kjølholt, J.; Gottschalck, F.; Baun, A. Environmental fate and behaviour of nanomaterials: New knowledge on important transformation processes. Environmental project No. 1594. The Danish Environmental Protection Agency, Copenhagen, DK, 2014.

(53) Hund-Rinke, K.; Simon, M. Ecotoxic effect of photocatalytic active nanoparticles (TiO2) on algae and daphnids. Environ. Sci. Pollut. Res. Int. 2006, 13 (4), 225-232.

(54) Amiano, I.; Olabarrieta, J.; Vitorica, J.; Zorita, S. Acute toxicity of nanosized TiO2 to Daphnia magna under UVA irradiation. Environ. Toxicol. Chem. 2012, 31 (11), 2564-2566.

(55) Holden, P. A.; Gardea-Torresdey, J. L.; Klaessig, F.; Turco, R. F.; Mortimer, M.; HundRinke, K.; Cohen Hubal, E. A.; Avery, D.; Barceló, D.; Behra, R.; et al. Considerations of Environmentally Relevant Test Conditions for Improved Evaluation of Ecological Hazards of Engineered Nanomaterials. Environ. Sci. Technol. 2016, 50 (12), 6124-6145.

(56) Mackevica, A.; Hansen, S. F. Release of nanomaterials from solid nanocomposites and consumer exposure assessment - a forward-looking review. Nanotoxicology 2016, 10(6), 641-653.

(57) Osmond-McLeod, M. J.; Oytam, Y.; Rowe, A.; Sobhanmanesh, F.; Greenoak, G.; Kirby, J.; McInnes, E. F.; McCall, M. J. Long-term exposure to commercially available sunscreens containing nanoparticles of $\mathrm{TiO} 2$ and $\mathrm{ZnO}$ revealed no biological impact in a hairless mouse 
Ettrup K., Kounina A., Hansen S. F., Meesters J. A. J., Vea E. B., Laurent A., 2017. Development of comparative toxicity potentials of $\mathrm{TiO}_{2}$ nanoparticles for use in life cycle assessment. Environmental Science and Technology 51, 4027-4037. DOI: 10.1021/acs.est.6b05049.

model. Part. Fibre Toxicol. 2016, 13 (1), 44.

(58) Wagener, S.; Dommershausen, N.; Jungnickel, H.; Laux, P.; Mitrano, D.; Nowack, B.; Schneider, G.; Luch, A. Textile Functionalization and Its Effects on the Release of Silver Nanoparticles into Artificial Sweat. Environ. Sci. Technol. 2016, 50 (11), 5927-5934.

(59) Sijm, D. T. H. M.; Rikken, M. G. J.; Rorije, E.; Traas, T. P.; McLAchlan, M. S.; Peijnenburg, W. J. G. M. Transport, accumulation and transformation processes. In Risk Assessment of Chemicals: An Introduction; van Leeuwen C. J., Vermeire T. G., Eds. Springer, Dordrecht, NL, 2007. 73-158.

(60) Hankin, S.; Peters, S.; Poland, C.; Foss Hansen, S.; Holmqvist, J.; Ross, B. L.; Varet, J.; Aitken, R. J. Specific Advice on Fulfilling Information Requirements for Nanomaterials under REACH. RIP-oN 2; Final Project Report; European Commission, 2011.

(61) Briggs, G. G.; Bromilow, R. H.; Evans, A. A. Relationships between lipophilicity and root uptake and translocation of non-ionised chemicals by barley. Pestic. Sci. 1982, 13 (5), 495504.

(62) Trapp, S.; Matthies, M.; Scheunert, I.; Topp, E. M. Modeling the bioconcentration of organic chemicals in plants. Environ. Sci. Technol. 1990, 24 (8), 1246-1252.

(63) Trapp, S.; Matthies, M. Generic one-compartment model for uptake of organic chemicals by foliar vegetation. Environ. Sci. Technol. 1995, 29 (9), 2333-2338.

(64) Larsen, H. F.; Hauschild, M. Evaluation of ecotoxicity effect indicators for use in LCIA. Int. J. Life Cycle Assess. 2007, 12 (1), 24-33.

(65) Larsen, H. F.; Hauschild, M. Z. GM-troph: A Low data demand ecotoxicity effect indicator for use in LCIA. Int. J. Life Cycle Assess. 2007, 12 (2), 79-91.

(66) Laurent, A., Harkema, J., Andersen, E.W., Owsianiak, M., Vea, E.B., Jolliet, O. Human health no-effect levels of $\mathrm{TiO}_{2}$ nanoparticles as a function of their primary size. Accepted in $J$. Nanopart. Res. (04/03/2017).

(67) Jovanović, B. Critical review of public health regulations of titanium dioxide, a human food additive. Integr. Environ. Assess. Manag. 2015, 11 (1), 10-20.

(68) Heinrich, U.; Fuhst, R.; Rittinghausen, S.; Creutzenberg, O.; Bellmann, B.; Koch, W.; Levsen, K. Chronic inhalation exposure of Wistar rats and two different strains of mice to diesel engine exhaust, carbon black, and titanium dioxide. Inhal. Toxicol. 1995, 7 (4), 533556.

(69) Crettaz, P.; Pennington, D.; Rhomberg, L.; Brand, K.; Jolliet, O. Assessing Human Health Response in Life Cycle Assessment Using ED10s and DALYs: Part 1 - Cancer Effects. Risk Anal. 2002, 22 (5), 931-946. 
Ettrup K., Kounina A., Hansen S. F., Meesters J. A. J., Vea E. B., Laurent A., 2017. Development of comparative toxicity potentials of $\mathrm{TiO}_{2}$ nanoparticles for use in life cycle assessment. Environmental Science and Technology 51, 4027-4037. DOI: 10.1021/acs.est.6b05049.

(70) Demou, E.; Peter, P.; Hellweg, S. Exposure to Manufactured Nanostructured Particles in an Industrial Pilot Plant. Ann. Occup. Hyg. 2008, 52 (8), 695-706.

(71) Koivisto, A. J.; Lyyränen, J.; Auvinen, A.; Vanhala, E.; Hämeri, K.; Tuomi, T.; Jokiniemi, J. Industrial worker exposure to airborne particles during the packing of pigment and nanoscale titanium dioxide. Inhal. Toxicol. 2012, 24 (12), 839-849.

(72) Johnston, B. D.; Scown, T. M.; Moger, J.; Cumberland, S. A.; Baalousha, M.; Linge, K.; van Aerle, R.; Jarvis, K.; Lead, J. R.; Tyler, C. R. Bioavailability of nanoscale metal oxides TiO2, CeO2, and ZnO to fish. Environ. Sci. Technol. 2010, 44 (3), 1144-1151.

(73) Pavagadhi, S.; Sathishkumar, M.; Balasubramanian, R. Uptake of Ag and TiO2 nanoparticles by zebrafish embryos in the presence of other contaminants in the aquatic environment. Water Res. 2014, 55, 280-291.

(74) Federici, G.; Shaw, B. J.; Handy, R. D. Toxicity of titanium dioxide nanoparticles to rainbow trout (Oncorhynchus mykiss): Gill injury, oxidative stress, and other physiological effects. Aquat. Toxicol. 2007, 84 (4), 415-430.

(75) Ramsden, C. S.; Smith, T. J.; Shaw, B. J.; Handy, R. D. Dietary exposure to titanium dioxide nanoparticles in rainbow trout, (Oncorhynchus mykiss): No effect on growth, but subtle biochemical disturbances in the brain. Ecotoxicology 2009, 18 (7), 939-951.

(76) Al-Jubory, A. R.; Handy, R. D. Uptake of titanium from $\mathrm{TiO}_{2}$ nanoparticle exposure in the isolated perfused intestine of rainbow trout: nystatin, vanadate and novel $\mathrm{CO}_{2}$-sensitive components. Nanotoxicology 2012, 7 (8), 1282-1301.

(77) Handy, R. D.; Cornelis, G.; Fernandes, T.; Tsyusko, O.; Decho, A.; Sabo-Attwood, T.; Metcalfe, C.; Steevens, J. A.; Klaine, S. J.; Koelmans, A. A.; et al. Ecotoxicity test methods for engineered nanomaterials: Practical experiences and recommendations from the bench. Environ. Toxicol. Chem. 2012, 31 (1), 15-31.

(78) Yeo, M. K.; Nam, D. H. Influence of different types of nanomaterials on their bioaccumulation in a paddy microcosm: A comparison of TiO2 nanoparticles and nanotubes. Environ. Pollut. 2013, 178, 166-172.

(79) Zhu, X.; Chang, Y.; Chen, Y. Toxicity and bioaccumulation of TiO2 nanoparticle aggregates in Daphnia magna. Chemosphere 2010, 78 (3), 209-215.

(80) Ma, X.; Gao, C. Uptake and accumulation of engineered nanomaterials and their phytotoxicity to agricultural crops. In Nanotechnologies in Food and Agriculture; Rai, M., Ribeiro C., Mattoso L., Duran N. Springer, Heidelberg, DE, 2015, 321-342.

(81) Zhang, P.; Ma, Y.; Zhang, Z.; 2015. Interactions Between Engineered Nanomaterials and Plants: Phytotoxicity, Uptake, Translocation, and Biotransformation. In: Nanotechnology and 
Ettrup K., Kounina A., Hansen S. F., Meesters J. A. J., Vea E. B., Laurent A., 2017. Development of comparative toxicity potentials of $\mathrm{TiO}_{2}$ nanoparticles for use in life cycle assessment. Environmental Science and Technology 51, 4027-4037. DOI: 10.1021/acs.est.6b05049.

Plant Sciences - Nanoparticles and Their Impact on Plants; Siddiqui M.H., Al-Whaibi M.H., Mohammad F., Eds. Springer, Heidelberg, DE, 2015, 77-99.

(82) Vittori-ntisari, L.; Carbone, S.; Gatti, A.; Vianello, G.; Nannipieri, P. Uptake and translocation of metals and nutrients in tomato grown in soil polluted with metal oxide (CeO2, Fe3O4, SnO2, TiO2) or metallic (Ag, Co, Ni) engineered nanoparticles. Environ. Sci. Pollut. Res. 2015, 22 (3), 1841-1853.

(83) Larue, C.; Laurette, J.; Herlin-Boime, N.; Khodja, H.; Fayard, B.; Flank, A. M.; Brisset, F.; Carriere, M. Accumulation, translocation and impact of TiO2 nanoparticles in wheat (Triticum aestivum spp.): Influence of diameter and crystal phase. Sci. Total Environ. 2012, 431, 197-208.

(84) Larue, C.; Veronesi, G.; Flank, A.-M.; Surble, S.; Herlin-Boime, N.; Carrière, M. Nanoparticles in wheat and rapeseed. J. Toxicol. Environ. Heal. Part A 2012, 75 (13-15), $722-734$.

(85) Rico, C. M.; Majumdar, S.; Duarte-Gardea, M.; Peralta-Videa, J. R.; Gardea-Torresdey, J. L. Interaction of nanoparticles with edible plants and their possible implications in the food chain. J. Agric. Food Chem. 2011, 59, 3485-3498.

(86) Schwab, F.; Zhai, G.; Kern, M.; Turner, A.; Schnoor, J. L.; Wiesner, M. R. Barriers, pathways and processes for uptake, translocation and accumulation of nanomaterials in plants - Critical review. Nanotoxicology 2016, 10 (3), 257-278.

(87) Dan, Y.; Zhang, W.; Xue, R.; Ma, X.; Stephan, C.; Shi, H. Characterization of gold nanoparticle uptake by tomato plants using enzymatic extraction followed by single-particle inductively coupled plasma-mass spectrometry analysis. Environ. Sci. Technol. 2015, 49 (5), 3007-3014.

(88) Bradfield, S. J.; Kumar, P.; White, J. C.; Ebbs, S. D. Zinc, copper or cerium accumulation from metal oxide nanoparticles or ions in sweet potato : Yield effects and projected dietary intake from. Plant Physiol. Biochem. 2017, 110, 128-137.

(89) Lützhøft H.-C. H.; Hartmann, N. B.; Brinch, A.; Kjølholt, J.; Baun, A. Environmental effects of engineered nanomaterials - Estimations of Predicted No-Effect Concentrations (PNECs). Environmental project No. 1787. The Danish Environmental Protection Agency, Copenhagen, DK, 2015.

(90) Lee, W. M.; An, Y. J. Effects of zinc oxide and titanium dioxide nanoparticles on green algae under visible, UVA, and UVB irradiations: No evidence of enhanced algal toxicity under UV pre-irradiation. Chemosphere 2013, 91 (4), 536-544.

(91) Vicario-Parés, U.; Castañaga, L.; Lacave, J. M.; Oron, M.; Reip, P.; Berhanu, D.; Valsami- 
Ettrup K., Kounina A., Hansen S. F., Meesters J. A. J., Vea E. B., Laurent A., 2017. Development of comparative toxicity potentials of $\mathrm{TiO}_{2}$ nanoparticles for use in life cycle assessment. Environmental Science and Technology 51, 4027-4037. DOI: 10.1021/acs.est.6b05049.

Jones, E.; Cajaraville, M. P.; Orbea, A. Comparative toxicity of metal oxide nanoparticles (CuO, ZnO and TiO2) to developing zebrafish embryos. J. Nanopart. Res. 2014, 16 (8), 2550.

(92) IARC. Titanium dioxide. IARC Monographs on the Evaluation of Carcinogenic Risks to Humans. IARC Monographs Volume 93.IARC, Lyon, FR, 2010.

(93) NIOSH. Occupational Exposure to Titanium Dioxide. Current Intelligence Bulletin 63. DHHS (NIOSH) Publication No. 2011-160. Department of Health and Human Services, Centers for Disease Control and Prevention, National Institute for Occupational Safety and Health: Atlanta, GA, USA, 2011.

(94) Clark, K.; van Tongeren, M.; Christensen, F. M.; Brouwer, D.; Nowack, B.; Gottschalk, F.; Micheletti, C.; Schmid, K.; Gerritsen, R.; Aitken, R.; et al. Limitations and information needs for engineered nanomaterial-specific exposure estimation and scenarios: recommendations for improved reporting practices. J. Nanoparticle Res. 2012, 14 (9), 1-14.

(95) Kühnel, D.; Busch, W.; Meißner, T.; Springer, A.; Potthoff, A.; Richter, V.; Gelinsky, M.; Scholz, S.; Schirmer, K. Agglomeration of tungsten carbide nanoparticles in exposure medium does not prevent uptake and toxicity toward a rainbow trout gill cell line. Aquat. Toxicol. 2009, 93 (2-3), 91-99.

(96) Patra, M.; Ma, X.; Isaacson, C.; Bouchard, D.; Poynton, H.; Lazorchak, J. M.; Rogers, K. R. Changes in agglomeration of fullerenes during ingestion and excretion in Thamnocephalus platyurus. Environ. Toxicol. Chem. 2011, 30 (4), 828-835.

(97) Hartmann, N. B.; Engelbrekt, C.; Zhang, J.; Ulstrup, J.; Kusk, K. O.; Baun, A. The challenges of testing metal and metal oxide nanoparticles in algal bioassays: titanium dioxide and gold nanoparticles as case studies. Nanotoxicology 2012, 7 (6), 1082-1094.

(98) Jacobs, R.; Meesters, J. A.; ter Braak, C. J. F.; van de Meent, D.; van der Voet, H. Combining exposure and effect modelling into an integrated probabilistic environmental risk assessment for nanoparticles. Environ. Toxicol. Chem. 2016, 35 (12), 2958-2967.

(99) Griffitt, R. J.; Luo, J.; Gao, J.; Bonzongo, J.-C.; Barber, D. S. Effects of particle composition and species on toxicity of metallic nanomaterials in aquatic organisms. Environ. Toxicol. Chem. 2008, 27 (9), 1972-1978.

(100) Christensen, F. M.; Johnston, H. J.; Stone, V.; Aitken, R. J.; Hankin, S.; Peters, S.; Aschberger, K. Nano-silver - feasibility and challenges for human health risk assessment based on open literature. Nanotoxicology 2010, 4 (3), 284-295.

(101) Christensen, F. M.; Johnston, H. J.; Stone, V.; Aitken, R. J.; Hankin, S.; Peters, S.; Aschberger, K. Nano-TiO2-feasibility and challenges for human health risk assessment based on open literature. Nanotoxicology 2011, 5 (2), 110-124. 
Ettrup K., Kounina A., Hansen S. F., Meesters J. A. J., Vea E. B., Laurent A., 2017. Development of comparative toxicity potentials of $\mathrm{TiO}_{2}$ nanoparticles for use in life cycle assessment. Environmental Science and Technology 51, 4027-4037. DOI: 10.1021/acs.est.6b05049.

828 (102) Aschberger, K.; Micheletti, C.; Sokull-Klüttgen, B.; Christensen, F. M. Analysis of currently available data for characterising the risk of engineered nanomaterials to the environment and human health — Lessons learned from four case studies. Environ. Int. 2011, 37 (6), 11431156.

832 (103) OECD. Report of the OECD Expert Meeting on the Physical Chemical Properties of 833 Manufactured Nanomaterials and Test Guidelines. Series on the Safety of Manufactured 834 Nanomaterials No. 41. ENV/JM/MONO(2014)15. OECD, Paris, FR, 2014. 